\title{
Association between Chinese or South Asian ethnicity and end-of-life care in Ontario, Canada
}

\author{
Christopher J. Yarnell MD, Longdi Fu MSc, Michael J. Bonares MD, Ayah Nayfeh MSc, Robert A. Fowler MDCM MS
}

Cite as: CMAJ 2020 March 16;192:E266-74. doi: 10.1503/cmaj.190655

See related article at www.cmaj.ca/lookup/doi/10.1503/cmaj.200201

\begin{abstract}
BACKGROUND: Ethnicity may be associated with important aspects of end-oflife care, such as what treatments are received, access to palliative care and where people die. However, most studies have focused on end-of-life care of white, Hispanic and black patients. We sought to compare end-of-life care delivered to people of Chinese and South Asian ethnicity with that delivered to others from the general population, in Ontario, Canada.
\end{abstract}

METHODS: In this population-based cohort study, we included all people who died in Ontario, Canada, between Apr. 1, 2004, and Mar. 31, 2015. People were identified as having Chinese or South
Asian ethnicity on the basis of a validated surname algorithm. We used modified Poisson regression analyses to assess location of death and care received in the last 6 months of life.

RESULTS: We analyzed 967339 decedents, including 18959 (2.0\%) of Chinese and $11406(1.2 \%)$ of South Asian ethnicity. Chinese (13.6\%) and South Asian (18.5\%) decedents were more likely than decedents from the general population (10.1\%) to die in the intensive care unit (ICU). The adjusted relative risk of dying in intensive care was 1.21 (95\% confidence interval [Cl] 1.15 to 1.27) for Chinese and 1.25 (95\% $\mathrm{Cl} 1.20$ to 1.30 ) for South Asian decedents. In their last 6 months of life, decedents of
Chinese and South Asian ethnicity experienced significantly more ICU admission, hospital admission, mechanical ventilation, dialysis, percutaneous feeding tube placement, tracheostomy and cardiopulmonary resuscitation than the general population.

INTERPRETATION: Decedents of Chinese and South Asian ethnicity in Ontario were more likely than decedents from the general population to receive aggressive care and to die in an ICU. These findings may be due to communication difficulties between patients and clinicians, differences in preferences about end-oflife care or differences in access to palliative care services.

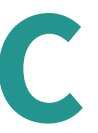

ulturally appropriate, patient-focused end-of-life care is an essential component of health care. Despite a preference to die at home, most Canadians die in hospitals and many receive end-of-life care in intensive care units (ICUs). ${ }^{1-3}$ Multiple factors contribute to this discrepancy, including uncertainty about the imminence of death, challenges in communication between health care teams and patients and families, poor health literacy and lack of access to palliative care resources. ${ }^{3-7}$ These factors may be more pronounced among people from minority ethnic groups. Differences in preferences for intervention at the end of life among ethnic groups may also influence care; the research showing a preference for dying at home included mostly white Canadians. ${ }^{1}$

People of Chinese and South Asian ethnicity are the most rapidly growing ethnic groups in Canada, yet little is known about their end-of-life care. ${ }^{8,9}$ Comparative studies from the United States have focused on black and Hispanic Americans ${ }^{8-13}$ and suggest that minority ethnicity is associated with lower family-rated quality of end-of-life care,${ }^{14}$ increased use of life-support technologies, ${ }^{13}$ and decreased use of advanced directives or hospice. ${ }^{6,12,15-17}$ Qualitative research describing end-of-life care for people of Chinese or South Asian ethnicities in international settings shows some common themes, including reluctance to share terminal diagnoses, emphasis on collective as opposed to individual decision-making, and attenuation of differences with acculturation. ${ }^{6,18,19}$ For people of Chinese ethnicity, research highlights the influence of Confucian philosophy and the role of children in decisions regarding elderly parents. ${ }^{20-23}$ For people of South Asian ethnicity, research emphasizes notions of karma, ambivalence toward the cultural appropriateness of hospices or sedating analgesic 
medications, and the influence of common South Asian religions including Islam, Buddhism, Sikhism or Hinduism. ${ }^{24-30}$

In 2011, Ontario had a population of 12851821 , of whom the 2 largest ethnic minority groups were South Asian (833 085, 6.5\%) and Chinese $(531635,4.1 \%) .{ }^{31}$ Previous research identified that people in Ontario who were born in South Asia or East Asia experienced end-of-life care that was different from that experienced by long-standing residents, but this analysis did not investigate patient ethnicity. ${ }^{32}$ We conducted this population-based analysis to describe end-of-life care delivered to people of Chinese and South Asian ethnicity compared with that delivered to others from the general population.

\section{Methods}

\section{Study design, setting and data sources}

We conducted a retrospective decedent cohort study analyzing patients who died in Ontario, Canada, between 2004 and 2015. Data regarding immigration status were obtained using the Permanent Resident Database maintained by Immigration, Refugees and Citizenship Canada. ${ }^{32}$ Identification of health care use before death was obtained using health administrative databases that were linked at the individual level: Registered Persons Database containing vital statistics on all people issued a provincial health card, Ontario Health Insurance Plan, Office of the Registrar General for Deaths, Discharge Abstract Database and National Ambulatory Care Reporting System..$^{33,34}$ These databases contain comprehensive coverage of care provided in hospitals. ${ }^{35}$

\section{Study cohort}

All individuals who died in Ontario between Apr. 1, 2004, and Mar. 31, 2015, were eligible, excluding those enrolled in Ontario's publicly funded health insurance plan for less than 6 months. People with missing baseline data $(<1 \%)$ were included only in unadjusted analyses.

Ethnicity was identified through a validated algorithm using surnames to identify patients of Chinese ethnicity (sensitivity $80.2 \%$, specificity $99.7 \%$ ) and South Asian ethnicity (sensitivity $50.4 \%$, specificity $99.7 \%$ ). ${ }^{36}$ This algorithm has been used to investigate multiple clinical questions in Ontario administrative health data. ${ }^{37-40}$ All decedents not identified as being of either Chinese or South Asian ethnicity were classified as being from the general population.

Patient characteristics included age, sex, socioeconomic position, place of residence at time of death, and cause of death. Health services data included palliative care physician visits, ICU admissions, hospital admissions and procedures during the final 6 months of life. The databases did not contain information on cardiopulmonary resuscitation (CPR) preferences or goals of care.

Decedents were classified as recently immigrated (since 1985) or long-standing resident (all others). For recently immigrated decedents, information obtained at the time of immigration application was available, including immigration class (economic, family, refugee and other), education level, language ability and country of birth.

\section{Outcomes}

The primary outcome described end-of-life care by location of death: ICU, acute care hospital, long-term-care facility (or nursing home), home or other (including hospice). The results are expressed as relative risks (RRs), comparing the proportions of decedents of Chinese or South Asian ethnicity with proportions of decedents from the general population who experienced a given outcome.

Secondary outcomes assessed interventions received in the last 6 months of life, including palliative care, hospital admission, ICU admission, mechanical ventilation, dialysis, percutaneous feeding tube, tracheostomy or CPR.

A decedent was classified as having received palliative care if there were administrative codes for palliative care visits in outpatient, inpatient, long-term care or complex continuing care settings (Appendix 1, available at www.cmaj.ca/lookup/suppl/ doi:10.1503/cmaj.190655/-/DC1). ${ }^{41}$ The data included home care services provided to patients given an "end-of-life" designation by their physicians, but did not include home care services provided to patients without such a designation or services paid for out of pocket by patients or families. ${ }^{41}$

\section{Statistical analysis}

We assessed the association between ethnicity and end-of-life care outcomes using modified Poisson regression to estimate RRs. ${ }^{42}$ Outcomes included location of death (ICU, acute care hospital, long-term-care facility, home or other, including hospice) and care received in the last 6 months (hospital admission, ICU admission, mechanical ventilation, dialysis, percutaneous feeding tube placement, tracheostomy, CPR and palliative care). Patient covariates included age, sex, income quintile, urban or rural residence, cause of death and immigration status. The analysis used generalized estimating equations with an exchangeable correlation structure to account for geographic clustering. ${ }^{43}$

Recently immigrated decedents were separately analyzed with additional covariates unique to immigrated decedents, to investigate how an ethnicity covariate affected previously observed differences in end-of-life care by region of birth for recently immigrated decedents. ${ }^{32}$

We performed post-hoc interaction analyses of ethnicity and immigration status, and ethnicity and age group. If modified Poisson regression models did not converge, we used logistic regression. Two-sided $p$ values less than 0.05 were considered significant, with no adjustment for multiple comparisons. We used SAS Enterprise Guide 6.1 and R 3.5 software.

\section{Ethics approval}

This study was approved by ICES, a prescribed entity allowing for use of patient information in approved research projects without patient consent.

\section{Results}

\section{Demographic and clinical characteristics}

We included 967339 decedents, of whom 18959 (2.0\%) were of Chinese ethnicity and 11406 (1.2\%) were of South Asian ethnicity according to the surname algorithm. The median age at death 
was 80 (interquartile range 68-87) years, with cardiovascular causes $(24.8 \%)$ the most common category of causes of death (Appendix 1). Compared with decedents from the general population, decedents of Chinese and South Asian ethnicity were less wealthy and more likely to live in an urban area (Table 1). The proportion of decedents who had immigrated to Canada since 1985 was higher among the decedents of Chinese $(39.7 \%)$ and South Asian (49.5\%) ethnicity than among decedents from the general population (3.7\%).

\section{End-of-life care}

Of the 967339 decedents, 99783 (10.3\%) died in intensive care. Compared with decedents from the general population, a higher propor- tion of decedents of Chinese (13.6\% v. $10.1 \%$, difference $3.4 \%, 95 \%$ confidence interval $[\mathrm{Cl}] 3.0 \%$ to $3.9 \%$ ) and South Asian ethnicity ( $18.5 \%$ v. $10.1 \%$, difference $8.3 \%, 95 \% \mathrm{Cl} 7.6 \%$ to $9.0 \%$ ) died in intensive care (Table 2 and Table 3). This increase persisted after adjustment for differences in age, sex, income, geography, cause of death and immigration status. The adjusted RR of dying in intensive care for decedents of Chinese ethnicity was 1.21 (95\% Cl 1.15 to 1.27) and for decedents of South Asian ethnicity was 1.25 (95\% Cl 1.20 to 1.30).

In the last 6 months of life, compared with decedents from the general population, decedents of Chinese and South Asian ethnicity experienced more ICU admission, hospital admission, mechanical ventilation, dialysis, percutaneous feeding tube placement, tracheostomy and CPR (Figure 1). Decedents of

Table 1: Baseline characteristics of decedents from the general population and of Chinese and South Asian ethnicity in Ontario, Canada, between 2004 and 2015

\section{No. (\%) of decedents}

\begin{tabular}{|c|c|c|c|c|}
\hline Characteristic & $\begin{array}{c}\text { General population } \\
\qquad n=936974\end{array}$ & $\begin{array}{c}\text { Chinese ethnicity } \\
n=18959\end{array}$ & $\begin{array}{l}\text { South Asian ethnicity } \\
\qquad n=11406\end{array}$ & $\begin{array}{c}\text { Total } \\
n=967339\end{array}$ \\
\hline \multicolumn{5}{|l|}{ Age, yr } \\
\hline$\leq 40$ & $27604(2.9)$ & $652(3.4)$ & $727(6.4)$ & $28983(3.0)$ \\
\hline $41-60$ & $115681(12.3)$ & $2513(13.3)$ & $1892(16.6)$ & $120086(12.4)$ \\
\hline $61-80$ & $351690(37.5)$ & $6613(34.9)$ & $5170(45.3)$ & $363473(37.6)$ \\
\hline$\geq 81$ & $441999(47.2)$ & $9181(48.4)$ & $3617(31.7)$ & $454797(47.0)$ \\
\hline \multicolumn{5}{|l|}{ Sex } \\
\hline Female & $470210(50.2)$ & $9254(48.8)$ & $5138(45.0)$ & $484602(50.1)$ \\
\hline Male & $466764(49.8)$ & $9705(51.2)$ & $6268(55.0)$ & 482737 (49.9) \\
\hline \multicolumn{5}{|l|}{ Income quintile* } \\
\hline 1 (lowest) & $216204(23.1)$ & $5113(27.0)$ & $3098(27.2)$ & $224415(23.2)$ \\
\hline 2 & $194244(20.7)$ & $4231(22.3)$ & $2882(25.3)$ & $201357(20.8)$ \\
\hline 3 & $180728(19.3)$ & $3246(17.1)$ & $2470(21.7)$ & $186444(19.3)$ \\
\hline 4 & $174531(18.6)$ & $3325(17.5)$ & $1696(14.9)$ & $179552(18.6)$ \\
\hline 5 (highest) & $165746(17.7)$ & $2625(13.8)$ & $1240(10.9)$ & $169611(17.5)$ \\
\hline \multicolumn{5}{|l|}{ Metropolitan influence zones $\dagger$} \\
\hline No (most rural) & $118238(12.6)$ & $243(1.3)$ & $136(1.2)$ & $118617(12.3)$ \\
\hline Weak & $293740(31.3)$ & $1183(6.2)$ & $818(7.2)$ & $295741(30.6)$ \\
\hline Moderate & $181461(19.4)$ & $1250(6.6)$ & $770(6.8)$ & $183481(19.0)$ \\
\hline Strong (least rural) & $343076(36.6)$ & $16273(85.8)$ & $9676(84.8)$ & $369025(38.1)$ \\
\hline \multicolumn{5}{|l|}{ Cause of death $\ddagger$} \\
\hline Cancer & 214708 (22.9) & $5091(26.9)$ & $1964(17.2)$ & $221763(22.9)$ \\
\hline Cardiovascular & $233492(24.9)$ & 3776 (19.9) & $2874(25.2)$ & $240142(24.8)$ \\
\hline Sepsis & $33452(3.6)$ & $834(4.4)$ & $479(4.2)$ & 34765 (3.6) \\
\hline Other & $455322(48.6)$ & $9258(48.8)$ & $6089(53.4)$ & $470669(48.7)$ \\
\hline \multicolumn{5}{|l|}{ Immigration status } \\
\hline Long-standing resident & $902594(96.3)$ & $11432(60.3)$ & $5760(50.5)$ & $919786(95.1)$ \\
\hline Recently immigrated resident & $34380(3.7)$ & $7527(39.7)$ & $5646(49.5)$ & $47553(4.9)$ \\
\hline
\end{tabular}

* Defined by average income for the postal code.

†Metropolitan influence zones classify geographic regions in Canada on the spectrum from urban to rural using residence, commuting and employment data. $\ddagger$ ategories defined in Appendix 1. 
Table 2: End-of-life care delivered to people of Chinese ethnicity compared with that delivered to others from the general population in Ontario, Canada, between 2004 and 2015

\section{No. $(\%)$ of decedents}

\begin{tabular}{|c|c|c|c|c|}
\hline Characteristic & $\begin{array}{l}\text { General population } \\
\qquad n=936974\end{array}$ & $\begin{array}{c}\text { Chinese ethnicity } \\
\qquad n=18959\end{array}$ & $\begin{array}{l}\text { Unadjusted absolute } \\
\text { difference, } \%(95 \% \mathrm{Cl})\end{array}$ & $\begin{array}{l}\text { Adjusted relative ris } \\
\qquad(95 \% \mathrm{Cl})^{\star}\end{array}$ \\
\hline \multicolumn{5}{|l|}{ Location of death } \\
\hline ICU & $95100(10.1)$ & $2578(13.6)$ & $3.4(3.0$ to 3.9$)$ & $1.21(1.15$ to 1.27$)$ \\
\hline Hospital & $323279(34.5)$ & $7773(41.0)$ & 6.5 (5.8 to 7.2 ) & 1.11 (1.09 to 1.13$)$ \\
\hline Long-term care & $75058(8.0)$ & $1628(8.6)$ & $0.6(0.2$ to 1.0$)$ & 0.97 (0.91 to 1.03$)$ \\
\hline Home & $381545(40.7)$ & $5805(30.6)$ & $-10.1(-10.8$ to -9.4$)$ & $0.83(0.80$ to 0.87$)$ \\
\hline Othert & $61992(6.6)$ & $1175(6.2)$ & $-0.4(-0.8$ to -0.1$)$ & $1.04(0.98$ to 1.11$)$ \\
\hline \multicolumn{5}{|c|}{ Interventions received in final 6 months of life } \\
\hline Hospital admission & $638684(68.2)$ & $14271(75.3)$ & 7.1 (6.5 to 7.7$)$ & 1.05 (1.04 to 1.06$)$ \\
\hline ICU admission & $181002(19.3)$ & $4017(21.2)$ & 1.9 (1.3 to 2.5$)$ & 1.05 (1.01 to 1.09$)$ \\
\hline Mechanical ventilation & $129205(13.8)$ & $3450(18.2)$ & $4.4(3.9$ to 5.0$)$ & $1.15(1.10$ to 1.20$)$ \\
\hline Dialysis & $32596(3.5)$ & $851(4.5)$ & 1.0 (0.7 to 1.3$)$ & 1.18 (1.09 to 1.27$)$ \\
\hline Percutaneous feeding tube & $28366(3.0)$ & $975(5.1)$ & 2.1 (1.8 to 2.4 ) & $1.27(1.19$ to 1.36$)$ \\
\hline Tracheostomy & $10465(1.1)$ & $318(1.7)$ & $0.6(0.4$ to 0.7$)$ & 1.13 (1.00 to 1.28$)$ \\
\hline CPR & $23459(2.5)$ & $733(3.9)$ & $1.4(1.1$ to 1.6$)$ & 1.17 (1.07 to 1.27$)$ \\
\hline Palliative care & $279619(29.8)$ & $6895(36.4)$ & 6.5 (5.8 to 7.2$)$ & 1.07 (1.05 to 1.09$)$ \\
\hline
\end{tabular}

Note: $\mathrm{Cl}=$ confidence interval, $\mathrm{CPR}=$ cardiopulmonary resuscitation, $\mathrm{ICU}=$ intensive care unit.

${ }^{*}$ Calculated from a modified Poisson regression model with generalized estimating equations. The model adjusted for age, sex, category of cause of death, immigration status, urbanization of address and income quintile.

tOther locations of death include complex continuing care and hospice.

Table 3: End-of-life care delivered to people of South Asian ethnicity compared with that delivered to others from the general population in Ontario, Canada, between 2004 and 2015

\section{No. $(\%)$ of decedents}

\begin{tabular}{|c|c|c|c|c|}
\hline Characteristic & $\begin{array}{c}\text { General population } \\
\qquad n=936974\end{array}$ & $\begin{array}{l}\text { South Asian ethnicity } \\
\qquad n=11406\end{array}$ & $\begin{array}{l}\text { Unadjusted absolute } \\
\text { difference, } \%(95 \% \mathrm{Cl})\end{array}$ & $\begin{array}{c}\text { Adjusted relative risk } \\
(95 \% \mathrm{Cl})^{\star}\end{array}$ \\
\hline \multicolumn{5}{|l|}{ Location of death } \\
\hline ICU & $95100(10.1)$ & $2105(18.5)$ & 8.3 (7.6 to 9.0$)$ & 1.25 (1.20 to 1.30$)$ \\
\hline Hospital & 323279 (34.5) & $4089(35.8)$ & $1.3(0.5$ to 2.2$)$ & 1.03 (1.01 to 1.06$)$ \\
\hline Long-term care & $75058(8.0)$ & $602(5.3)$ & $-2.7(-3.1$ to -2.3$)$ & 0.69 (0.64 to 0.75$)$ \\
\hline Home & $381545(40.7)$ & $3511(30.8)$ & $-9.9(-10.8$ to -9.1$)$ & $0.88(0.85$ to 0.90$)$ \\
\hline Other ${ }^{\dagger}$ & $61992(6.6)$ & $1099(9.6)$ & $3.0(2.5$ to 3.6$)$ & 1.21 (1.14 to 1.28$)$ \\
\hline \multicolumn{5}{|c|}{ Interventions received in final 6 months of life } \\
\hline Hospital admission & $638684(68.2)$ & $8224(72.1)$ & 3.9 (3.1 to 4.8$)$ & 1.03 (1.02 to 1.04$)$ \\
\hline ICU admission & $181002(19.3)$ & $3388(29.7)$ & 10.4 (9.5 to 11.2 ) & 1.21 (1.17 to 1.24$)$ \\
\hline Mechanical ventilation & $129205(13.8)$ & $2960(26.0)$ & $12.2(11.4$ to 13.0$)$ & 1.27 (1.23 to 1.31$)$ \\
\hline Dialysis & $32596(3.5)$ & $842(7.4)$ & 3.9 (3.4 to 4.4$)$ & 1.46 (1.36 to 1.57$)$ \\
\hline Percutaneous feeding tube & $28366(3.0)$ & $761(6.7)$ & 3.6 (3.2 to 4.1$)$ & 1.48 (1.37 to 1.59$)$ \\
\hline Tracheostomy & 10465 (1.1) & $316(2.8)$ & 1.7 (1.4 to 2.0$)$ & 1.38 (1.22 to 1.56$)$ \\
\hline CPR & $23459(2.5)$ & $750(6.6)$ & 4.1 (3.6 to 4.5$)$ & 1.45 (1.34 to 1.56$)$ \\
\hline Palliative care & $279619(29.8)$ & $3155(27.7)$ & $-2.2(-3.0$ to -1.4$)$ & 0.94 (0.92 to 0.97$)$ \\
\hline
\end{tabular}

Note: $\mathrm{Cl}=$ confidence interval, $\mathrm{CPR}=$ cardiopulmonary resuscitation, $\mathrm{ICU}=$ intensive care unit.

${ }^{\star}$ Calculated from a modified Poisson regression model with generalized estimating equations. The model adjusted for age, sex, category of cause of death, immigration status, urbanization of address and income quintile.

tOther locations of death include complex continuing care and hospice. 


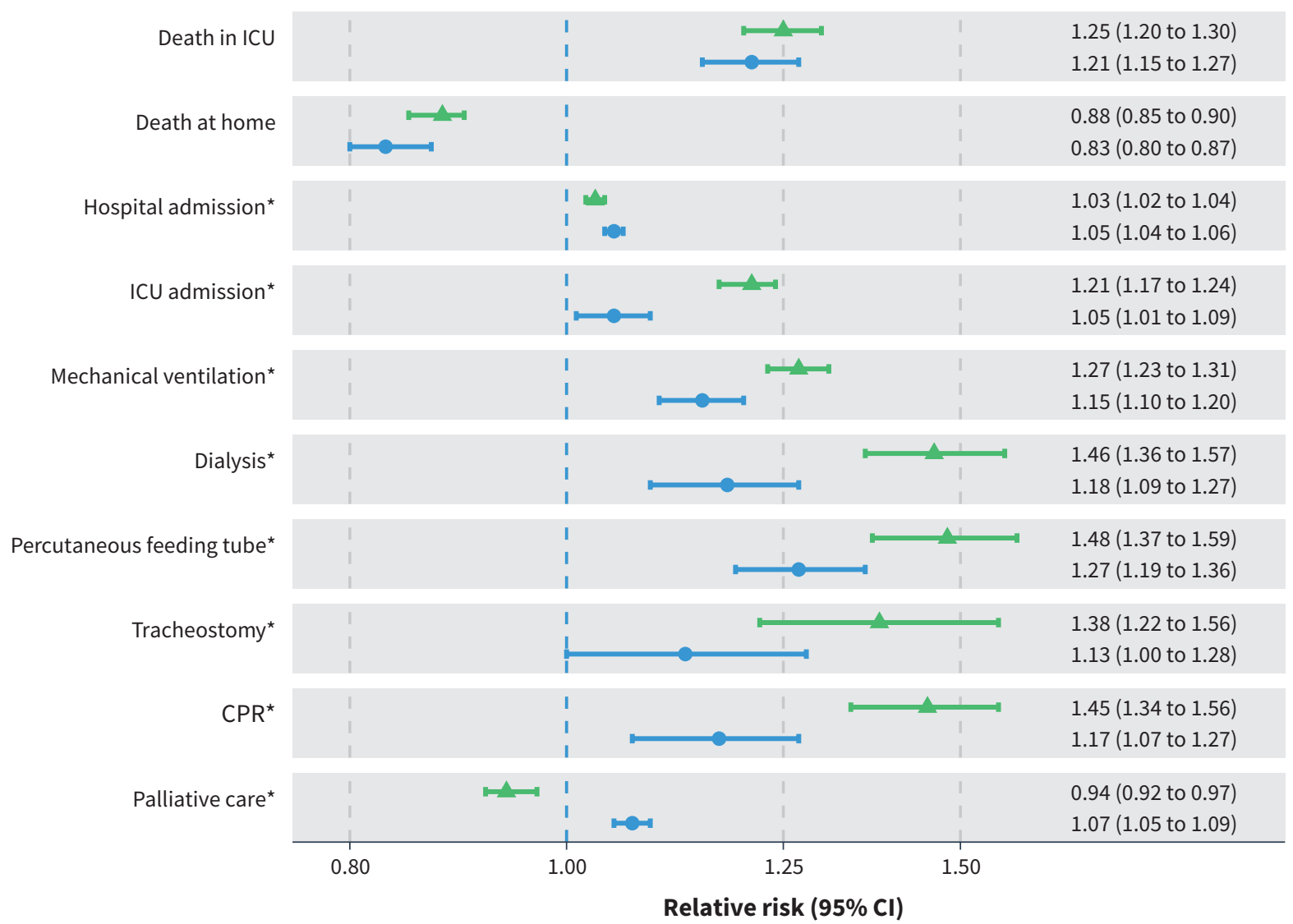

Ethnicity

Figure 1: Forest plot showing the ratio of the proportions of decedents from each ethnicity experiencing each of the major study outcomes. Each comparison shows the relative risk (RR) of experiencing the outcome among Ontario decedents of either Chinese or South Asian ethnicity compared with the Ontario decedent general population. Each RR is derived from a modified Poisson regression model with generalized estimating equations incorporating age, sex, geography, socioeconomic position, cause of death and immigration status. Relative risks greater than 1 correspond to an increased RR of the outcome among Ontarians of Chinese or South Asian ethnicity. Note: $\mathrm{Cl}=$ confidence interval, $\mathrm{CPR}=$ cardiopulmonary resuscitation, $\mathrm{ICU}=$ intensive care unit. ${ }^{*}$ Interventions received in final 6 months of life.

Chinese ethnicity had more, and decedents of South Asian had fewer, interactions with palliative care clinicians than decedents from the general population (Figure 1).

\section{Recently immigrated population subgroup}

Our analysis included a subgroup of 47553 recently immigrated people, of whom 7527 (15.8\%) were of Chinese ethnicity and 5646 (11.9\%) were of South Asian ethnicity (Appendix 1, Supplemental Table E1). Among decedents of Chinese ethnicity, there was an increase in the unadjusted RR of dying in intensive care when we compared recent immigrants with long-standing residents (14.4\% v. $13.1 \%$, difference $1.3 \%, 95 \% \mathrm{Cl} 0.3 \%$ to $2.3 \%$ ). Among decedents of South Asian ethnicity, for the same comparison, there was no difference ( $18.5 \%$ v. $18.5 \%$, difference $0.0 \%$, $95 \% \mathrm{Cl}-1.4 \%$ to $1.4 \%)$. Among recently immigrated decedents, the adjusted RR of dying in intensive care for those of Chinese ethnicity compared with the general population was $1.08(95 \% \mathrm{Cl}$ 0.97 to 1.20 ), and for those of South Asian ethnicity compared with the general population it was 0.93 ( $95 \% \mathrm{Cl} 0.86$ to 0.99). This model included the same covariates as the base model as well as covariates unique to the recently immigrated decedent cohort (landing date, region of birth, language ability and education level on arrival, immigration type and years in Ontario at death).

\section{Sensitivity analyses}

Because the surname algorithms favour specificity over sensitivity, many decedents who identified as being of Chinese or South Asian ethnicity were classified as decedents from the general population. We estimated 4681 misclassified Chinese decedents and 11225 misclassified South Asian decedents on the basis of test sensitivities and calculated that even if every decedent of Chinese ethnicity misclassified as being from the general population was not in the ICU at death, the unadjusted result would still retain significance (Appendix 1, Supplemental Figure E1). Similarly, the proportion of decedents of South Asian ethnicity misclassified as being from the general population who died in the ICU would have 


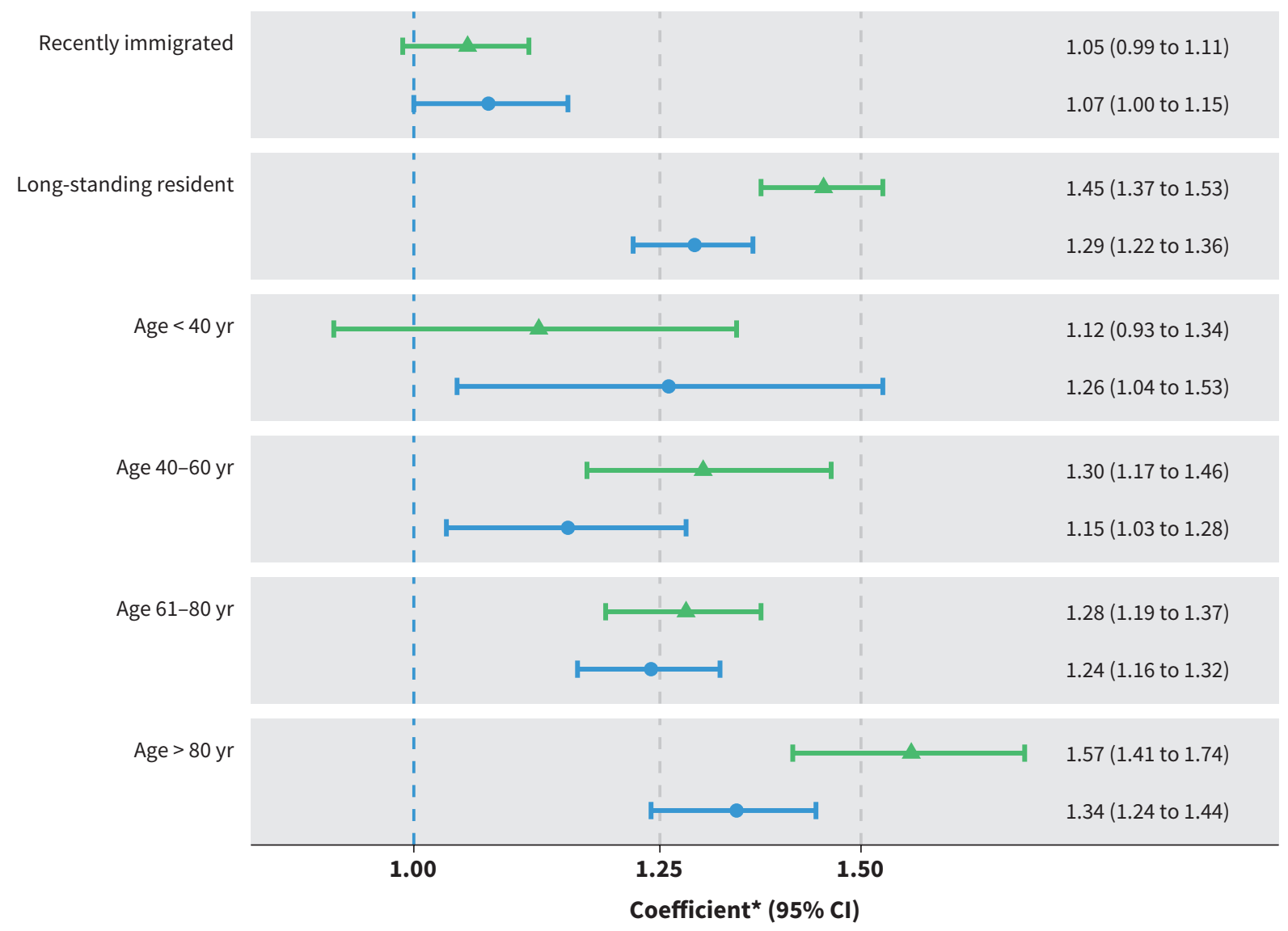

Ethnicity Chinese v. general population

Figure 2: Forest plot showing the coefficients of the 2 interaction analyses (age by ethnicity and immigration status by ethnicity) with respect to the outcome of death in the intensive care unit (ICU) compared with all other locations. Each row shows the relative risk (RR) of being in the ICU at the time of death for decedents within the described subgroup comparing Ontario decedents of either Chinese or South Asian ethnicity with Ontario decedents from the general population. Each coefficient is derived from a regression model with generalized estimating equations incorporating age, sex, geography, socioeconomic position, cause of death and immigration status. Note: $\mathrm{Cl}=$ confidence interval. *Coefficients for the interaction between immigration status and ethnicity are RRs from a modified Poisson regression model, and coefficients for the interaction between age and ethnicity are odds ratios from a logistic regression model owing to convergence difficulties with a modified Poisson model. Relative risks greater than 1 correspond to an increased RR of being in intensive care at death among Ontarians of Chinese or South Asian ethnicity.

to be $3.2 \%$ or less (as opposed to the $19 \%$ proportion observed in correctly classified decedents) for the unadjusted differences to become not significant (Appendix 1, Supplemental Figure E2).

The interaction analysis of recent immigration and ethnicity showed greater differences in location of death among decedents who were long-standing residents relative to those who recently immigrated (Figure 2). The interaction analysis of age and ethnicity suggests increasing differences in location of death at ages greater than 80 years when comparing decedents of Chinese or South Asian ethnicity and decedents from the general population (Figure 2).

\section{Interpretation}

Among decedents in Ontario, those of Chinese or South Asian ethnicity were more likely to receive aggressive end-of-life care and to die in intensive care than those from the general population. Differences in end-of-life care between cohorts persisted despite adjustment for age, sex, cause of death, socioeconomic position, urban versus rural geography, and immigration status.

The finding of more aggressive end-of-life care among decedents of Chinese or South Asian ethnicity is similar to the findings of other large-scale quantitative analyses assessing end-of-life care for people from ethnic minorities in North America such as Hispanic or black people. ${ }^{16,44,45}$ Although each ethnic group has multiple unique underlying contributors to these findings, some factors such as provider-patient ethnicity discordance, decreased socioeconomic resources and discrimination may be common to different minority ethnicities. ${ }^{5,46,47}$

We found contrasting results with respect to receipt of palliative care in the final 6 months of life, with decedents of South Asian ethnicity less likely, and decedents of Chinese ethnicity 
more likely, to receive palliative care relative to decedents from the general population. The results of qualitative research are conflicting regarding the attitudes toward and use of advanced care planning among people from East Asia, and further research is needed to better understand this finding. ${ }^{41,48,49}$

This study adds to the previously described association between immigration status and end-of-life care by showing that both recent immigration status and Chinese or South Asian ethnicity are independently associated with more aggressive end-oflife care. ${ }^{32}$ The previously identified association between recent immigration and more aggressive end-of-life care persisted even after adjustment for ethnicity. However, the interaction analyses emphasized that the largest differences in end-of-life care by ethnicity were seen in decedents who were long-standing residents. It is not possible to fully separate immigration and ethnicity in this analysis, because there were no data on birthplaces of longstanding residents, and many decedents of Chinese and South Asian ethnicity classified as long-standing residents may have immigrated to Canada before $1985 .{ }^{36}$

The observed variation in end-of-life care by ethnicity has multiple potential explanations, including patient preferences, health literacy, communication barriers, cultural differences, clinician behaviour, use of advanced directives, and differences in service accessibility. ${ }^{46}$ Differences in patient and family preferences may relate to religious and cultural beliefs, practices regarding death, notions of filial responsibility, or a preference for family-centred as opposed to individual decisionmaking. ${ }^{18,19,21-24,26-28,41,43}$ Previous research documented an association between minority ethnicity and decreased knowledge of advanced care planning. ${ }^{12,50}$ Communication difficulties may exist between patients of Chinese and South Asian ethnicity and health care professionals because of differences in languages spoken, culture, beliefs about end-of-life care and communication styles, which may manifest as cultural insensitivity and lead to a lack of trust. ${ }^{3,28-30,51-54}$ Some clinical settings may have fewer health care professionals of minority-ethnicity backgrounds. ${ }^{55}$ Lastly, people of Chinese or South Asian ethnicity may have fewer financial or social resources to help them pay for or provide non-publicly funded outpatient endof-life care. ${ }^{3,6,24}$

\section{Limitations}

This observational study has several limitations. The surname algorithm to identify patient ethnicity is optimized for specificity but has only moderate sensitivity. Although the algorithm was derived for use in the databases employed in this study, it has been validated only once in that database. ${ }^{36}$ We attempted to quantify the potential impact of misclassified decedents in our sensitivity analyses. The introduction of confounding as a result of the surname algorithm is possible. For example, the South Asian surname list includes more names of Sikh, Hindu or Sri Lankan backgrounds and fewer names of Christian or Muslim backgrounds. ${ }^{36}$ Differences in comorbidities or cause of death not captured by the category of cause of death are another potential source of unmeasured confounding. The adjustment for geography is also fallible because some people may be able to access relatively scarce resources, such as palliative care, regardless of geographic location. ${ }^{56}$ The findings describe care in Ontario and may have limited generalizability to other Canadian provinces or territories, or other countries. This research is further limited by the lack of qualitative data on medical decision-making, the attitudes toward treatment and the experience of end-of-life care for people of Chinese or South Asian ethnicities. Lastly, we had no data about the language or health literacy, religion, or goals of care for patients or families.

\section{Conclusion}

Among decedents in Ontario, people of Chinese and South Asian ethnicity were more likely than people from the general population to receive aggressive care and to die in an ICU. These differences may relate to preferences of patients or their substitute decision-makers, health literacy, decision-making or communication with health care professionals, or access to care.

\section{References}

1. Heyland DK, Dodek P, Rocker G, et al. What matters most in end-of-life care: perceptions of seriously ill patients and their family members. CMAJ 2006;174: 627-33.

2. Heyland DK, Cook DJ, Rocker GM, et al. Defining priorities for improving endof-life care in Canada. CMAJ 2010;182:E747-52.

3. Fraser J. Palliative and end-of-life care provincial roundtable report: a report from parliamentary assistant John Fraser to the minister of health and longterm care. Toronto: Queen's Printer for Ontario; 2016. Available: www.health. gov.on.ca/en/public/programs/palliative/pdf/palliative_report.pdf (accessed 2018 July 9).

4. Steinhauser KE, Christakis NA, Clipp EC, et al. Factors considered important at the end of life by patients, family, physicians, and other care providers. JAMA 2000;284:2476-82

5. Kwak J, Haley WE. Current research findings on end-of-life decision making among racially or ethnically diverse groups. Gerontologist 2005;45:634-41.

6. Ha-Redeye O, Latif R, Pirzada K. Integrating religious and cultural supports into quality care in the last stages of life in Ontario. Toronto: Law Commission of Ontario; 2017. Available: https://papers.ssrn.com/sol3/papers.cfm?abstract_ id=2962433 (accessed 2018 July 11).

7. Frost DW, Cook DJ, Heyland DK, et al. Patient and healthcare professional fac tors influencing end-of-life decision-making during critical illness: a systematic review. Crit Care Med 2011;39:1174-89.

8. LoPresti MA, Dement F, Gold HT. End-of-life care for people with cancer from ethnic minority groups: a systematic review. Am J Hosp Palliat Care 2016;33: 291-305.

9. Lackan NA, Eschbach K, Stimpson JP, et al. Ethnic differences in in-hospital place of death among older adults in California: effects of individual and contextual characteristics and medical resource supply. Med Care 2009;47: 138-45.

10. Hanchate A, Kronman AC, Young-Xu Y, et al. Racial and ethnic differences in end-of-life costs: Why do minorities cost more than whites? Arch Intern Med 2009;169:493-501.

11. Byhoff E, Harris JA, Langa KM, et al. Racial and ethnic differences in end-of-life medicare expenditures. J Am Geriatr Soc 2016;64:1789-97.

12. Portanova J, Ailshire J, Perez C, et al. Ethnic differences in advance directive completion and care preferences: What has changed in a decade? J Am Geriatr Soc 2017;65:1352-7.

13. Barnato AE, Chang C-CH, Lave JR, et al. The paradox of end-of-life hospital treatment intensity among black patients: a retrospective cohort study. J Palliat Med 2018;21:69-77. 
14. Lee JJ, Long AC, Curtis JR, et al. The influence of race/ethnicity and education on family ratings of the quality of dying in the ICU. J Pain Symptom Manage 2016;51:9-16.

15. Barnato AE, Anthony DL, Skinner J, et al. Racial and ethnic differences in preferences for end-of-life treatment. J Gen Intern Med 2009;24: 695-701.

16. Brown CE, Engelberg RA, Sharma R, et al. Race/ethnicity, socioeconomic status, and healthcare intensity at the end of life. J Palliat Med 2018;21: 1308-16.

17. Givens JL, Tjia J, Zhou C, et al. Racial and ethnic differences in hospice use among patients with heart failure. Arch Intern Med 2010;170:427-32.

18. Wright AA, Stieglitz $\mathrm{H}$, Kupersztoch YM, et al. United States acculturation and cancer patients' end-of-life care. PLoS One 2013;8:e58663.

19. Zheng RS, Guo QH, Dong FQ, et al. Chinese oncology nurses' experience on caring for dying patients who are on their final days: a qualitative study. Int $J$ Nurs Stud 2015;52:288-96.

20. Mjelde-Mossey LA, Chan CLW. Survey on death and dying in Hong Kong: attitudes, beliefs, and preferred end-of-life care. Soc Work Health Care 2007; 45:49-65.

21. Ho ZJM, Radha Krishna LK, Yee CPA. Chinese familial tradition and western influence: a case study in Singapore on decision making at the end of life. J Pain Symptom Manage 2010;40:932-7.

22. Gu X, Cheng W. Culture understanding of the discrepancy in end-of-life care implementation in China. BMJ Support Palliat Care 2012;2:A43.

23. Tay K, Yu Lee RJ, Sim SW, et al. Cultural influences upon advance care planning in a family-centric society. Palliat Support Care 2017;15:665-74.

24. Worth A, Irshad T, Bhopal R, et al. Vulnerability and access to care for South Asian Sikh and Muslim patients with life limiting illness in Scotland: prospective longitudinal qualitative study. BMJ 2009;338:b183.

25. Ebrahim S, Bance S, Bowman KW. Sikh perspectives towards death and endof-life care. J Palliat Care 2011;27:170-4.

26. Bloomer MJ, Al-Mutair A. Ensuring cultural sensitivity for Muslim patients in the Australian ICU: considerations for care. Aust Crit Care 2013;26:193-6.

27. Venkatasalu MR, Arthur A, Seymour J. Talking about end-of-life care: the perspectives of older South Asians living in East London. J Res Nurs 2013;18: 394-406.

28. Cowan MM. The lived experiences of the Sikh population of south east England when caring for a dying relative at home. Int J Palliat Nurs 2014;20: 179-86.

29. Khosla N, Washington KT, Regunath $\mathrm{H}$. Perspectives of health care providers on US South Asians' attitudes toward pain management at end of life. Am J Hosp Palliat Care 2016;33:849-57.

30. Weerasinghe S, Maddalena V. Negotiation, mediation and communication between cultures: end-of-life care for South Asian immigrants in Canada from the perspective of family caregivers. Soc Work Public Health 2016; 31:665-77.

31. Population and dwelling counts highlight tables, 2011 census. Ottawa: Statistics Canada; 2016. Available: www12.statcan.gc.ca/census-recensement/2011/dp -pd/hlt-fst/pd-pl/Table-Tableau.cfm?LANG=Eng\&T=101\&S=50\&O=A (accessed 2020 Feb. 22).

32. Yarnell CJ, Fu L, Manuel D, et al. Association between immigrant status and end-of-life care in Ontario, Canada. JAMA 2017;318:1479-88.

33. International Statistical Classification of Diseases and Related Health Problems, tenth revision. Geneva: World Health Organization; 2015. Available: http:// apps.who.int/classifications/icd10/browse/2016/en (accessed 2018 Mar. 21).

34. Juurlink D, Preyra C, Croxford R, et al. Canadian Institute for Health Information Discharge Abstract Database: a validation study. Toronto: ICES; 2006.

35. Glazier RH, Zagorski BM, Rayner J. Comparison of primary care models in Ontario by demographics, case mix and emergency department use, 2008/09 to 2009/10. Toronto: ICES; 2012.
36. Shah BR, Chiu M, Amin S, et al. Surname lists to identify South Asian and Chinese ethnicity from secondary data in Ontario, Canada: a validation study. BMC Med Res Methodol 2010;10:42.

37. Ke CH, Morgan S, Smolina K, et al. Is cardiovascular risk reduction therapy effective in South Asian, Chinese and other patients with diabetes? A population-based cohort study from Canada. BMJ Open 2017;7:e013808.

38. Chiu M, Gatov E, Zaheer J, et al. Postdischarge service utilisation and outcomes among Chinese and South Asian psychiatric inpatients in Ontario, Canada: a population-based cohort study. BMJ Open 2018;8:e020156.

39. Carsley S, Pope EI, Anderson LN, et al. Temporal trends in severe obesity prev alence in children and youth from primary care electronic medical records in Ontario: a repeated cross-sectional study. CMAJ Open 2019;7:E351-59.

40. Wanigaratne S, Uppal P, Bhangoo M, et al. Sex ratios at birth among secondgeneration mothers of South Asian ethnicity in Ontario, Canada: a retrospective population-based cohort study. J Epidemiol Community Health 2018;72: 1044-51.

41. Dobbs D, Park NS, Jang Y, et al. Awareness and completion of advance directives in older Korean-American adults. J Am Geriatr Soc 2015;63:565-70.

42. Yelland LN, Salter AB, Ryan P. Performance of the modified Poisson regression approach for estimating relative risks from clustered prospective data. Am J Epidemiol 2011;174:984-92

43. Kwak J, Salmon JR. Attitudes and preferences of Korean-American older adults and caregivers on end-of-life care. J Am Geriatr Soc 2007;55:1867-72.

44. Chertoff J, Olson A, Alnuaimat H. Does admission to the ICU prevent African American disparities in withdrawal of life-sustaining treatment? Crit Care Med 2017;45:e1083-6.

45. Kirtane K, Downey L, Lee SJ, et al. Intensity of end-of-life care for patients with hematologic malignancies and the role of race/ethnicity. J Palliat Care 2018; 21:1466-71.

46. Fang ML, Sixsmith J, Sinclair S, et al. A knowledge synthesis of culturally- and spiritually-sensitive end-of-life care: findings from a scoping review. BMC Geriatr 2016;16:107.

47. Johnson KS. Racial and ethnic disparities in palliative care. J Palliat Med 2013; 16:1329-34.

48. Thomas R, Wilson DM, Justice C, et al. A literature review of preferences for end-of-life care in developed countries by individuals with different cultural affiliations and ethnicity. J Hosp Palliat Nurs 2008;10:142-61.

49. Evans N, Meñaca A, Koffman J, et al. Cultural competence in end-of-life care: terms, definitions, and conceptual models from the British literature. J Palliat Med 2012;15:812-20.

50. Luk Y, Ngai C, Chau SS, et al. Clinicians' experience with and attitudes toward discussing advance directives with terminally ill patients and their families in a Chinese community. J Palliat Med 2015;18:794-8.

51. Periyakoil VS, Neri E, Kraemer H. No easy talk: a mixed methods study of doctor reported barriers to conducting effective end-of-life conversations with diverse patients. PLoS One 2015;10:e0122321.

52. O'Connor M, Poon EWH, Hsu JC-Y. The complexities of communicating palliative care in Chinese-based languages. Prog Palliat Care 2015;23:85-7.

53. Barnato AE, Mohan D, Downs J, et al. A randomized trial of the effect of patient race on physicians' intensive care unit and life-sustaining treatment decisions for an acutely unstable elder with end-stage cancer. Crit Care Med 2011;39: 1663-9.

54. Kwak J, Ko E, Kramer BJ. Facilitating advance care planning with ethnically diverse groups of frail, low-income elders in the USA: perspectives of care managers on challenges and recommendations. Health Soc Care Community 2014;22:169-77.

55. Munoz B, Garrett E, Reese D, et al. Barriers to Employment of African American professionals in hospice: a qualitative study with African American social work students. Am J Hosp Palliat Care 2015;32:280-5.

56. Collier R. Access to palliative care varies widely across Canada. CMAJ 2011; 183:E87-8. 
Competing interests: None declared.

This article has been peer reviewed.

Affiliations: Interdepartmental Division of Critical Care Medicine (Yarnell, Fowler), Department of Medicine, University of Toronto; Mount Sinai Hospital (Yarnell); Institute of Health Policy, Management and Evaluation (Yarnell, Nayfeh, Fowler), University of Toronto; ICES (Fu); Division of Palliative Medicine (Bonares), Department of Medicine, University of Toronto; Sunnybrook Health Sciences Centre (Fowler), Toronto, Ont.

Contributors: Christopher Yarnell contributed to the concept, study design, literature review, data analysis and data interpretation. Longdi Fu contributed to the study design and data analysis. Michael Bonares contributed to the data interpretation. Ayah Nayfeh contributed to the study design, concept and data interpretation. Robert Fowler contributed to the concept, study design, literature review, data analysis and data interpretation. Christopher Yarnell contributed to the writing, table and figure creation, appendix creation and critical review. Longdi Fu and Michael Bonares contributed to the critical review. Ayah Nayfeh contributed to the critical review and writing Robert Fowler contributed to the writing, table and figure creation, funding and critical review. All authors gave final approval of the version to be published and agreed to be accountable for all aspects of the work.

Funding: The study was funded by the Canadian Institutes of Health Research (CIHR), Heart and Stroke Foundation of Ontario, the Canadian Frailty Network Centre of Excellence and the University of Toronto Integrating Challenge Fund. The funders had no role in the design and conduct of the study; collection, management, analysis, and interpretation of the data; preparation, review, or approval of the manuscript; nor in the decision to submit the manuscript for publication.

Acknowledgements: The authors thank Dr. Baiju Shah for thoughtful feedback and advice regarding the manuscript and use of the surname-based algorithm. The authors also thank Immigration, Refugees and Citizenship Canada for providing access to the Permanent Resident Database of landed immigrants.

Disclaimers: This study was supported by ICES, which is funded by an annual grant from the Ontario Ministry of Health and Long-Term Care (MOHLTC). The opinions, results and conclusions reported in this paper are those of the authors and are independent from the funding sources. No endorsement by ICES, Immigration, Refugees and Citizenship Canada or the Ontario MOHLTC is intended or should be inferred.

Parts of this report are based on Ontario Registrar General information on deaths, the original source of which is ServiceOntario. The views expressed therein are those of the authors and do not necessarily reflect those of the Ontario Registrar General or Ministry of Government and Consumer Services.

Parts of this material are based on data and/or information compiled and provided by the Canadian Institute for Health Information (CIHI). However, the analyses, conclusions, opinions and statements expressed in the material are those of the authors, and not necessarily those of $\mathrm{CIHI}$.

These data sets were linked using unique encoded identifiers and analyzed at ICES.

Accepted: Jan. 10, 2020

Correspondence to: Robert Fowler, rob.fowler@sunnybrook.ca 